\title{
Genome-wide association studies: a powerful tool for neurogenomics
}

\author{
Matthew C. Cowperthwaite, Ph.D., ${ }^{1,2}$ Deepankar Mohanty, ${ }^{3}$ \\ AND Mark G. BuRnetT, M.D. ${ }^{1}$ \\ ${ }^{1}$ NeuroTexas Institute, St. David's Medical Center; ${ }^{2}$ Center for Systems and Synthetic Biology; and \\ ${ }^{3}$ Section of Neurobiology, The University of Texas at Austin, Texas
}

\begin{abstract}
As their power and utility increase, genome-wide association (GWA) studies are poised to become an important element of the neurosurgeon's toolkit for diagnosing and treating disease. In this paper, the authors review recent findings and discuss issues associated with gathering and analyzing GWA data for the study of neurological diseases and disorders, including those of neurosurgical importance. Their goal is to provide neurosurgeons and other clinicians with a better understanding of the practical and theoretical issues associated with this line of research. A modern GWA study involves testing hundreds of thousands of genetic markers across an entire genome, often in thousands of individuals, for any significant association with a particular disease. The number of markers assayed in a study presents several practical and theoretical issues that must be considered when planning the study. Genome-wide association studies show great promise in our understanding of the genes underlying common neurological diseases and disorders, as well as in leading to a new generation of genetic tests for clinicians. (DOI: 10.3171/2010.10.FOCUS09186)
\end{abstract}

\section{Key WoRds • neurogenomics $\quad$ genetics $\bullet$ neurosurgery}

A goal of molecular genetics is to discover the genetic architecture of human phenotypes, especially diseases. The research community has recently made great strides toward associating loci (genes) with phenotypes (diseases), but much work remains. ${ }^{80}$ These advances have resulted from significant increases in the scale and power of genetic-linkage tests, which have grown from candidate-gene analyses to GWA studies.

Genome-wide association studies are intended to address some of the shortcomings of traditional candidategene linkage tests. Classic linkage studies are typically difficult to conduct, at least in part because they require a priori knowledge about the biology of the disease under study (to select candidate genes) as well as a familiarity with the genetic variants (that is, mutations) in the candidate genes that could alter function or expression. ${ }^{113} \mathrm{Ad}-$ ditionally, there is an inherent bias in the candidate-gene approach stemming from the typically small number of genes that are selected for testing. The low-throughput nature of candidate-gene studies obviously makes them ill suited for testing roughly 30,000 genes and the millions of observed genetic variants in the human genome.

There has been a significant increase in the number of GWA studies being conducted, with $\sim 400$ published to

Abbreviations used in this paper: GWA = genome-wide association; HWE = Hardy-Weinberg equilibrium; SNP = single-nucleotide polymorphism. date. ${ }^{52,53}$ In general, these studies have 1) reinforced the importance of the genetic variation that underlies phenotypic variation, 2) illustrated that genetic variation almost always results from multiple Mendelian mutations rather than a single mutation, and 3) demonstrated that genetic variation typically explains only a small fraction of the observed phenotypic variation..$^{4,80,114}$ Within the field of neuroscience, recent GWA studies have provided insights into the genetic basis of many common neurological diseases and disorders (Table 1). Such studies have been conducted for conditions including Parkinson disease, ${ }^{39,67,93,113}$ malignant gliomas, ${ }^{23,95,109,143}$ multiple sclerosis, ${ }^{7,29,90}$ Alzheimer disease, ${ }^{15,18,41,72,73}$ autism, $, 3,82,45,75,107,133$ schizophrenia, ${ }^{25,119,138}$ lumbar disc disease, ${ }^{131}$ idiopathic scoliosis, ${ }^{43,140}$ and restless-leg syndrome. ${ }^{36,139}$

Without doubt, the field of genomics is going to play a central role in the clinical care of the future neurological patient. Physicians will therefore need to have at least a basic understanding of the research tools and concepts routinely used in this field. The purpose of this review is to familiarize the clinician with the fundamentals of GWA studies and to highlight their potential clinical application.

\section{Genome-Wide Association Models}

Recent progress toward understanding human genetic variation has advanced genetic-linkage and genet- 
TABLE 1: Genome-wide association studies of common diseases and disorders of the brain, spine, and nervous system*

\begin{tabular}{|c|c|}
\hline Condition Studied & Reference \\
\hline \multicolumn{2}{|l|}{ neurooncology } \\
\hline glioma & 109 \\
\hline high-grade glioma & 143 \\
\hline neuroblastoma & 77 \\
\hline high-risk neuroblastoma & 24 \\
\hline \multicolumn{2}{|l|}{ cerebrovascular disease } \\
\hline intracranial aneurysm & 20 \\
\hline hemorrhagic stroke & 9 \\
\hline ischemic stroke & $47,79,144$ \\
\hline \multicolumn{2}{|l|}{ neurological disease } \\
\hline $\begin{array}{l}\text { age-related macular } \\
\text { degeneration }\end{array}$ & 62 \\
\hline Alzheimer disease & $\begin{array}{l}2,15,18,26,41,72,73,96,103 \\
\quad 135,136\end{array}$ \\
\hline amyotrophic lateral sclerosis & $21,27,34,35,38,63,105,129,130$ \\
\hline Creutzfeldt-Jakob susceptibility & 81 \\
\hline multiple sclerosis & $6,7,12,28,29,57,59,90$ \\
\hline Parkinson disease & $42,76,93$ \\
\hline progressive supranuclear palsy & 82 \\
\hline restless legs syndrome & $36,104,139$ \\
\hline \multicolumn{2}{|l|}{ brain function \& physiology } \\
\hline cognition & 97,108 \\
\hline memory & 94 \\
\hline pain & 60 \\
\hline brain vol & 12 \\
\hline sleep & 46 \\
\hline $\begin{array}{l}\text { attention deficit hyperactivity } \\
\text { disorder }\end{array}$ & $5,64,65,68,83,87,117$ \\
\hline autism & 75,133 \\
\hline bipolar disorder & $13,40,51,106,115,116,137,145$ \\
\hline major depressive disorder & 85,120 \\
\hline panic disorder & 91 \\
\hline neuroticism & 111,128 \\
\hline schizophrenia & $\begin{array}{l}25,58,61,66,88,89,110,112,118 \\
\quad 119,121,132,138\end{array}$ \\
\hline personality dimensions & 123 \\
\hline \multicolumn{2}{|l|}{ addiction } \\
\hline alcohol dependence & 125 \\
\hline $\begin{array}{l}\text { methamphetamine } \\
\text { dependence }\end{array}$ & 126 \\
\hline nicotine dependence & $17,19,37,124,127$ \\
\hline
\end{tabular}

\footnotetext{
* Compiled from information contained in the National Human Genome
} Research Institute GWA study catalog. ${ }^{52,53}$ ic-association studies from candidate-gene analyses to GWA studies. ${ }^{98}$ The power of the GWA approach lies in the breadth and number of genetic variants tested during the course of a study. The GWA study also has the advantage of being an unbiased search for the genetic variants associated with a particular disease and therefore offers the possibility of discovering new associations of genes and pathways with diseases. ${ }^{4}$

\section{Genome-Wide Association Theory}

A phenotype is an observable trait produced by an underlying genotype. The genetic differences among individuals in the human population are commonly called "mutations" and most frequently are single-nucleotide changes within the DNA sequences of genes. ${ }^{11,80}$ Many mutations are expected to be harmful and thus to be removed from the population by natural selection. Fewer mutations are expected to be beneficial or fitness neutral, and such mutations can persist in a population over time while proceeding to fixation (every individual carries it) or loss (lost by the actions of selection and drift); with either fate, any genetic variation is lost and therefore not observable. Prior to being fixed or lost, a mutation is carried by only part of the population and is referred to as a "polymorphism." Single-nucleotide polymorphisms are commonly used as genetic markers in GWA studies and are the focus of this review-although alternative genetic features can be used for GWA studies. These alternatives may be particularly useful for GWA studies of psychiatric disorders, in which genetic features such as gene copynumber variations $\mathrm{s}^{14,45,107,119}$ and gross chromosomal rearrangements ${ }^{8}$ appear to be important to the genetic etiology of this class of diseases.

The aim of a typical GWA study is to associate one or more SNPs with a particular disease phenotype (Fig. 1). The tested SNPs are not expected to be the causal genetic factors; rather, they are used to mark ("tag") particular regions of chromosomes that likely contain many genetic variants in high linkage disequilibrium with the tested SNP. Linkage disequilibrium occurs when 2 or more alleles at distinct genetic loci occur together significantly more or less frequently than expected by chance based on the constituent allele frequencies. Single-nucleotide polymorphisms are therefore an efficient way to screen many mutations at once, and thus identify chromosomal locations within which the true causal variants are likely to reside. In fact, the true causal variant may not itself be a nucleotide mutation - it may be an insertion or deletion mutation.

Genome-wide association studies differ in their assumptions about the type of genetic variation underlying the disease of interest. Most such studies operate under the "common disease/common variant" hypothesis, which proposes that phenotypic variation is the result of many common SNPs, each of which contributes only a modest effect. ${ }^{100}$ An alternative hypothesis, the "multiple rare variant" hypothesis, proposes that phenotypic variation results from the potentially more modest effects of many rare SNPs. ${ }^{98}$ These two hypotheses are not necessarily mutually exclusive-the variation underlying a disease may fall into both categories; rather they are in- 


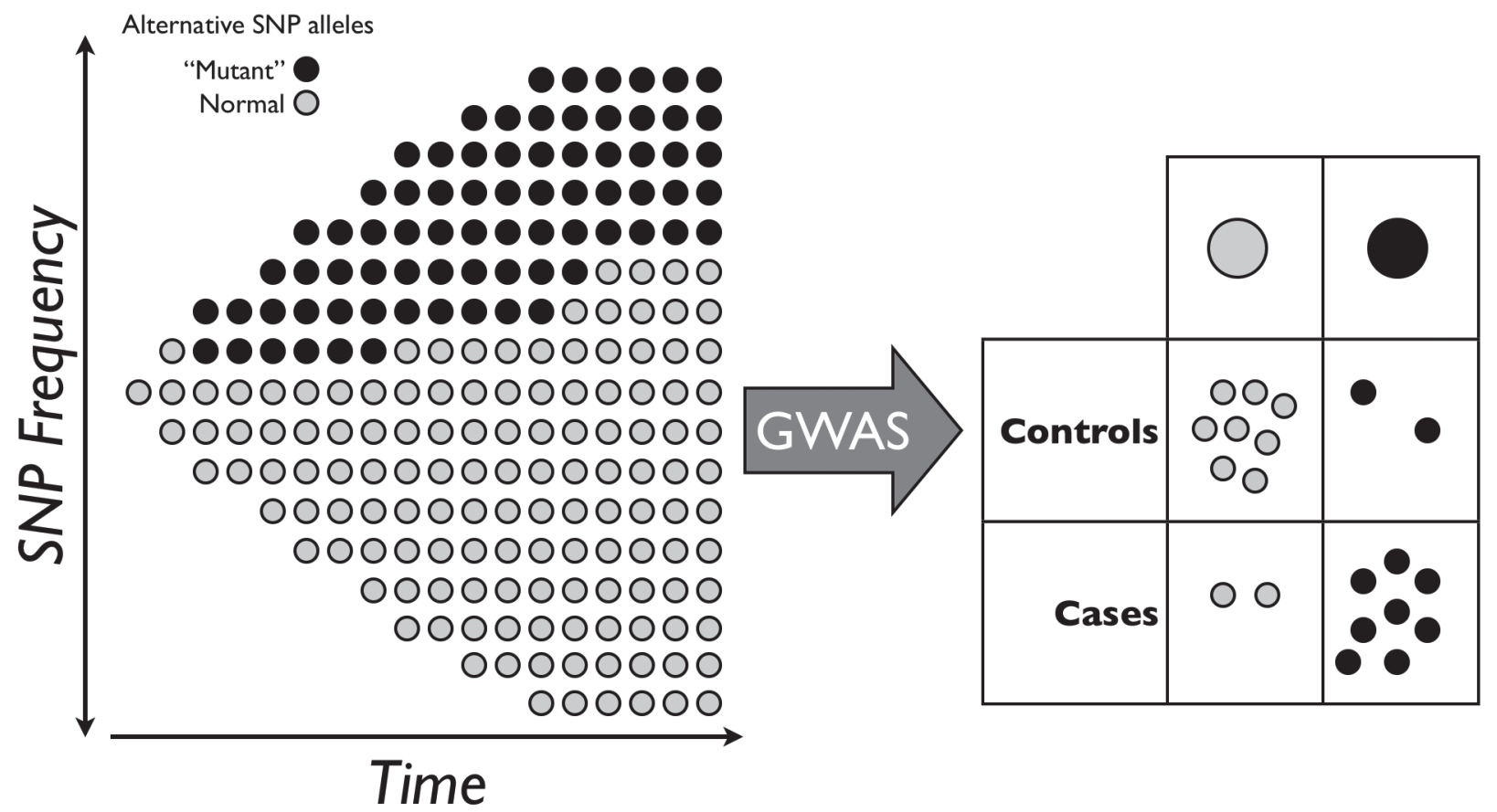

FIG. 1. Schematic representation of a GWA study. Left: A mutation (black circles) entering and spreading through a population over time. Right: A contingency table in which the mutation is significantly more abundant among the cases than the controls.

tended to guide the design, analysis, and interpretation of GWA studies.

Genetic variation can interact differently to produce the particular disease under study. It can interact additively, in which case alleles confer a mean effect that does not depend on the state of other alleles, or nonadditively, which means that the effect of an allele results from dominance effects and epistatic interactions with other loci. Additive genetic variation is most commonly considered in GWA studies, in which SNPs are typically considered as independent entities. ${ }^{4}$ Recently, there has been significant progress toward developing statistical models that assess nonadditive genetic effects, and these models promise to greatly enhance the scope and power of GWA studies..$^{30,32}$

\section{Genome-Wide Association Study Design}

The design of a GWA study primarily depends on the specific project goals, but practical factors such as budget and time must be considered as well. The most common design for a GWA study is the case-control format, in which there is a cohort of cases (affected individuals) and a cohort of controls (unaffected individuals). The individuals in the case cohort are assumed to have a greater prevalence of disease-causing alleles than those in the control cohort, ${ }^{80}$ a hypothesis that can be assessed by one or more statistical methods discussed below.

Power is the most critical aspect to consider when designing a GWA study. Study power determines the likelihood that a trial will detect significant genetic differences between case and control populations, if any such differences truly exist. Sample size profoundly affects the study power, and, in general, the largest sample that is feasible to genotype should be used. Study power can also be increased by carefully controlling for any population substructure and by cautiously selecting the control population. . $^{411,80}$

The individuals in the case and control populations are assumed to be "unrelated," which means that their ancestral relationships are distant and therefore unknown. ${ }^{11}$ However, the case and control individuals should not be so unrelated that there are distinct subgroups that share a common ancestry (for example, Western European or African heritage). When such subgroups exist, there is said to be population substructure or population stratification, which can be especially problematic when correlated with the case-control delineation. Population stratification can produce false-positive signals because some genetic variants can occur at different frequencies in the two groups as a result of ancestry, even though they are unrelated to the disease under study. Many statistical methods exist to control for population stratification ${ }^{11,80}$ and have been implemented in common software packages such as PLINK.${ }^{99}$ Furthermore, recent evidence has suggested that many concerns about population stratification may be overinflated; however, every effort should be made to eliminate its effects. ${ }^{11,80,137}$

Selection of the control population is crucial to the success of a GWA study. Common-control populations, which are genotyped populations that can be used across studies, have been successfully utilized in GWA studies. ${ }^{137}$ The main concerns about common controls are the presence of population stratification and the potential loss of power given the presence of latent (undiagnosed) disease 
in the control population. A study-specific control population is almost always ideal, but can greatly increase the time and cost of a GWA study (controls must be genotyped) and is subject to selection bias when differences, in addition to the disease under study, exist between cases and controls ${ }^{80}$ Historical controls, which are previously genotyped individuals used in current studies, have the potential to reduce study power when there is significant genetic divergence between extant cases and historical controls. Historical controls may be the best option available, however, and recent evidence has suggested that some of the drawbacks may be overcome by increases in sample size. ${ }^{137}$

An alternative study design is "family-based association" in which genetic tests are performed within families. Family-based association studies offer strong control of background genetic differences at the cost of overall study power. The additional costs associated with studying large numbers of families and recent improvements in statistical methods to control for population stratification make family-based studies attractive for only specialized circumstances. ${ }^{80}$

\section{Genome-Wide Association Study Methods}

\section{Genotype Calling}

Genotyping is the phase in which an instrument determines ("calls") the genotype, or state of both alleles, at every SNP locus tested. Genotype calling is typically performed in a high-throughput manner by using highly automated instruments, such as those commercially available from Affymetrix and Illumina. Commercial genotyping instruments use high-density microarrays of SNPs ("SNP chips," informally) that have been identified through projects such as the International HapMap Consortium. ${ }^{56}$

The latest generation of commercial SNP genotyping platforms can routinely test $\sim 2$ million genetic loci in a single assay. The loci include $\sim 1$ million SNPs and an approximately equal number of copy-number variants; a state-of-the-art instrument with robotic automation can generate $~ 40-50$ million genotypes per day. However, investigators in most published studies have used earlier genotyping platforms that tested $\sim 300,000-500,000$ SNPs. One advantage of commercial genotyping platforms is that the selection of high-quality SNPs to test is no longer a challenge left to individual researchers. The latest genotyping platforms include SNPs that are spaced, on average, 1-2 kilobases apart and cover $\sim 95 \%$ of the human genome, including sex chromosomes and mitochondrial genomes. Current genotyping instruments poorly sample regions of the human genome with infrequent restriction enzyme sites, which precludes isolating SNPs in these regions. An additional benefit of commercial platforms is that they lead to further standardization of the SNPs tested across studies.

\section{Quality Control of Genotype Data}

Genome-wide association studies produce enormous amounts of data, and therefore data quality is of para- mount importance. Rigorous quality control measures must be implemented at each stage of the study-from DNA extraction and amplification through to analyzing and interpreting the data. A common source of errors is genotype calling, which must strike a balance between stringency and call rate. If base calling is excessively stringent, then most markers will have a low call rate, which can inflate the false-positive rate. ${ }^{11}$ On the other hand, overly relaxed genotype calling will produce significant numbers of miscalled genotypes. Finally, a threshold call rate must be selected, and SNPs whose call rates fall below this threshold should be excluded from consideration. Individuals with low overall call rates should be removed because such rates suggest that their DNA samples may be problematic.

Each marker should be tested in the control population to ensure it is in HWE, which describes the expected genotype frequencies (based on allele frequencies) in a randomly mating population in the absence of selection, mutation, and migration. ${ }^{50}$ Extreme deviations from HWE might be symptomatic of genotype calling errors, and such markers can generally be removed with impunity. ${ }^{80}$ On the other hand, moderate deviations from HWE may be expected in the cases, and therefore the inclusion threshold should not remove these markers because they may provide additional information when searching for disease-associated SNPs. ${ }^{11,142}$ The HWE inclusion threshold must be carefully selected to balance overall inclusiveness with the purging of potentially problematic markers. A flexible and powerful approach is the use of the observed distribution of HWE values for each marker to determine an appropriate threshold for inclusion. ${ }^{137}$

There are a few remaining aspects to consider when implementing quality-control measures. Individuals whose genotype does not agree with their stated ethnicity or sex should not be included. Methods should be implemented to ensure all individuals in the study share a common ancestral background (for example, all of Western European descent) to minimize population substructure. Individuals with evidence of genetic syndromes (for example, fragile-X syndrome or trisomy 21) should also be excluded. In family-based studies, markers with unusually high rates of Mendelian errors-potentially a sign of frequent miscalling of genotypes-should be discarded..$^{11,80}$

\section{Testing for Association}

After obtaining a high-quality set of genotypes, a GWA study typically moves into the analysis phase during which SNPs are tested for their association with the phenotype of interest. This phase essentially consists of applying one or more statistical tests of association to each marker tested. There are several statistical models available, although the viable options may be constrained by the study design (for example, phenotypic variable). The statistics underlying these methods can be quite difficult to understand, and therefore only the general features of the most common tests are discussed herein. The interested reader is encouraged to investigate one of many recent reviews for more detailed treatments of GWA study statistics. ${ }^{11,134}$

A significant problem with many tests of association 
is the extensive multiple-testing burden; ${ }^{11,80,134}$ this problem becomes more significant as the number of SNPs tested increases. Multiple-testing burden refers to the increased false-positive rate that results from performing multiple independent tests on the same data set. Several methods exist to correct the $p$ values for multiple testing and reduce the likelihood of false-positive signals..$^{10,54,134}$ The most conservative approach is a Bonferroni correction in which individual $\mathrm{p}$ values are each multiplied by $N$ (the number of SNPs tested) to maintain the false-positive rate at a desired level. More flexible and relaxed falsediscovery rate (FDR) calculations can be used as well. ${ }^{16}$ Such corrections yield a greater number of potential SNPs positively associated with the disease under study, but also create a greater risk of including false-positive associations. Simulation models can also be used to empirically determine a threshold $p$ value that appropriately balances overall inclusiveness with false-positive risk. Under any multiple-testing correction approach, the required $p$ value for attaining significance for any particular SNP is exceedingly small because modern GWA studies effectively conduct hundreds of thousands of statistical tests.

The most basic test for a single SNP in a case-control design is that for independence between the 2 rows (cases and controls) and 3 columns (genotypes) of a contingency table. ${ }^{11}$ A chi-square or Fisher exact test would be an appropriate statistical test. Alternatively, one could use a Cochran-Armitage test, which is based on the differences in allele counts rather than genotype counts, and may be more powerful for complex traits for which the contribution of individual SNPs is thought to be roughly additive. ${ }^{80}$

More advanced statistical approaches based on regression modeling are routinely used when analyzing GWA data. Logistic regression models are suitable for case-control studies in which the phenotype is binary (for example, presence or absence of a disease), whereas a linear regression or an ANOVA model is suitable for testing continuous phenotypes (for example, degree of spine curvature in a scoliosis study). One advantage of using regression models is that epistatic interactions between SNPs can be readily incorporated into the model, as can other covariates such as age or sex. An important theoretical consideration is that regression-based methods assume that phenotypes are observed prospectively, whereas most GWA studies select individuals based on phenotype and then determine the genotype. ${ }^{11}$

Family-based association studies model SNP flow through pedigrees. Software packages such as MERLIN and LAMP (freely available at http://csg.sph.umich. edu) are widely used suites of programs for the analysis of large pedigree data sets. ${ }^{1}$ MERLIN is designed to test quantitative trait association, whereas LAMP ${ }^{69,70}$ is intended for discrete trait association. Both software programs use likelihood statistics to assess the relative probabilities of alternative patterns of gene flow through the pedigrees in the data set.

\section{Interpretation of Results}

Once a set of associated SNPs has been identified, a search for additional evidence to support the observed association must begin. Ideally, the study would be replicated with a different population of cases and controls to ensure that the same SNPs would be identified in these new individuals. Such replication may not be feasible, however, for reasons such as cost or time.

Vendor-supplied annotation files can be used to determine the physical and genomic location of each SNP within the genome. The annotation for each SNP may also include additional information, such as whether the SNP is located within a gene (intronic/exonic) or an intergenic region. Using this information, one can search databases such as Entrez for additional DNA, RNA, or protein sequence information, or Medline can be queried for other studies corroborating an observed SNP association. For example, genes adjacent to an associated SNP can be checked to determine if any have prior evidence linking them to the disease under study, which could identify genomic locations that might be good targets for more extensive sequencing efforts.

\section{Limitations of GWA Studies}

\section{Theoretical Limitations}

There is appreciable work to be done on the practical and analytical front for improving the current generation of GWA methods. First and foremost, even the most powerful GWA study can only explain a small percentage of the observed phenotypic variation. This fact partially emphasizes the need for models and methods that explicitly consider the interactions of genes with their environment. Gene-by-environment interactions present a significant practical challenge to GWA studies; it is extremely difficult to determine the relevant times and environmental variables to measure. ${ }^{31,33}$ In the future, statistical methods that consider the interactions between multiple genetic variants must be advanced. ${ }^{32,55}$ The power to model and detect epistatic interactions among mutations in a genome offers great hope to more completely explain phenotypic variation and uncover a greater number of loci. Loci that are not strongly associated with a trait individually may be very strongly associated when considered in combination with other mutations.

Genome-wide association studies only test for a statistically significant association of a marker with a trait and cannot make a causal statement. The direct test for causality between associated SNPs and their flanking genes would involve the mutation of each candidate gene and the determination of the resulting phenotype. Obviously, this is impossible with humans, but other organisms, such as yeast, mice, and primates, may be good surrogate models for the human disease. One or more of these model organisms might be useful in refining the set of associated SNPs and further understanding the genes and pathways mutated in diseased individuals. It is a long road from a GWA study to determining which genes and pathways are defective in the diseased state; however, GWA analysis can be an important first step in identifying otherwise unknown genes and pathways involved in diseases. 


\section{Practical Limitations}

At present, the most significant practical limitation for GWA studies is cost. Genotyping is expected to cost $\sim$ \$500 per individual, not considering the necessary instrumentation. Current genotyping instruments require a significant initial investment of roughly $\$ 300,000$. Alternatively, research service providers can be contracted for some or all stages of data production (DNA extraction, genotyping, and so forth). Significant costs may also be associated with obtaining sufficient high-quality data, especially for rare diseases with a low incidence. Moreover, significant time and resources may be required to generate the genetic data (genotyping) for the control population.

The large amounts of data generated during the course of a GWA study must be processed on relatively powerful computers with a large storage capacity. Additionally, computer software may need to be developed inhouse to store and analyze the data, or existing software programs may need to be acquired. Commercial software packages are available to analyze the data, and there are freely available options as well.

\section{Clinical Applications of GWA Studies}

\section{Genetic Testing}

In addition to identifying a set of alleles associated with a particular disease, the GWA approach can be used to identify risk alleles, that is, those that appear to confer an increased risk for developing a disease. Genetic risks have been based on family history or candidate gene testing. Genome-wide association approaches may one day be able to provide a comprehensive picture of an individual's risk for developing any of a wide range of disorders.

Although it has been proposed that risk calculations based on GWA data might ultimately replace those based on family history, ${ }^{102}$ genetic tests have gained only limited acceptance in the medical community. ${ }^{48,49}$ The clinical utility of genetic testing has been difficult to demonstrate for a variety of reasons, but significant effort is currently being expended to overcome these obstacles. Single-nucleotide polymorphisms implicated in the most powerful GWA studies typically explain only a small fraction of the observed variation for a disease, which partly stems from a combination of methodological and practical limitations. Genome-wide association tests carry significant direct costs. It has been difficult to demonstrate their cost-effectiveness because 1) risk loci have typically low penetrance, 2) the benefits of genetic testing are hard to quantify because treatment for the disease may improve over time or a patient's adherence to preventive measures may decline over time, and 3) there is a potential cost to the patient in terms of stigmatization by society or psychological stress resulting from his or her knowledge about potential future disease. ${ }^{101}$ Nonetheless, GWA screens have been conducted for a number of diseases of neurosurgical importance. ${ }^{114}$

Malignant glioma is the most common type of primary brain tumor, and the prognosis remains poor despite surgical and oncological advancements. ${ }^{43,74}$ As in other types of cancer, there is great interest in identifying susceptibility loci for these aggressive tumors. Such loci would allow for the estimation of the risk of developing malignant glioma in a particular individual during his or her lifetime. Significantly at-risk individuals could be monitored more closely, with the hope that increased surveillance might lead to earlier detection and better treatment outcomes.

Recently, authors of a large GWA study were able to identify 5 genetic loci that appear to confer a significant risk for the development of malignant gliomas. ${ }^{109}$ The SNPs identified potentially support the importance of the cyclin-dependent kinase inhibitor 2A-cyclin-dependent kinase 4 (CDKN2A-CDK4) signaling pathway, as well as the genes involved in genomic stability and telomere preservation. A few of the genes and chromosomal regions have been implicated in other types of cancer. Interestingly, 2 of these loci appear to be associated with a greater risk for the development of high-grade gliomas. ${ }^{143}$ One of the chromosomal regions identified is the $9 \mathrm{p} 21$ region in which the $C D K N 2 B$ gene resides. This gene participates in the control of cell division and is frequently deleted in high-grade gliomas. The other identified chromosomal region is $20 \mathrm{q} 13$ in which RTEL1 is located. The RTEL1 gene encodes a DNA helicase that is critical for the maintenance of telomere length.

Idiopathic scoliosis is the most common childhood spine disorder, affecting almost $3 \%$ of children globally. ${ }^{140,141}$ The disease appears to cluster within families, although the precise mode of inheritance has yet to be determined. A recent GWA study revealed significant linkage of a region of chromosome 8 with idiopathic scoliosis, specifically with the $C H D 7$ gene. ${ }^{44}$

Lumbar disc disease is a significant source of disability, and one of the most common disorders seen in neurosurgical practices. ${ }^{92}$ A recent small-scale GWA study demonstrated an association between a region of chromosome 21 and lumbar disc disease. ${ }^{131}$ The results of this study are encouraging, although larger and more densely sampled GWA studies must be conducted to corroborate the data. Furthermore, lumbar disc disease may present special problems relating to phenotype scoring since many individuals carry asymptomatic disc herniations.

\section{Diagnostics, Tumor Grading, and Prognosis}

The GWA study framework also holds great promise for molecular diagnostics in medicine. Molecular diagnostics use genetic markers to ascertain the clinical status of a patient's tissue sample. For example, a patient's brain tumor tissue sample is traditionally sent for anatomical pathology analysis. In the future, a patient's specimen may be sent to a genetics laboratory for analysis. The potential advantages of genetics-based diagnostics are that such analyses are typically unambiguous, unbiased, and completely objective. There is still much work to be done for this field to move from potential applications to effective clinical solutions.

Recently, significant progress has been made toward developing molecular diagnostics for brain tumors, in particular malignant gliomas. For example, there is a great deal of interest in developing tumor-grading meth- 
ods based on the genetic states of tumors rather than their anatomical appearance. ${ }^{86,122}$ These methods would use genetic markers as an adjunct to traditional grading of tumors by a pathology lab. There is also significant interest in developing tumor prognosis classifiers based on genetic markers, with some recent success. ${ }^{95}$ Progress has been made in developing artificial-intelligence classifier models that predict survival time based on the genomic expression patterns of select genetic loci. ${ }^{71,78}$

\section{Personalized Medicine and Tumor Drugs}

Lastly, we note that GWA studies may one day lead to clinical regimens that are individually tailored to each patient. For instance, genetic testing is routinely being done for oligodendrogliomas, with the $1 \mathrm{p} / 19 \mathrm{q}$ screen for chemotherapeutic effectiveness. However, the GWA approach permits screening for more markers in a single sweep and offers much more precision in associating genotypes with clinically important phenotypes. In addition, understanding genes, as opposed to chromosome arms, will allow for a deeper understanding into the molecular genetic mechanisms behind drug function and metabolism, and lead to better therapies in the future..$^{84,122}$

\section{Conclusions}

Genome-wide association studies hold great promise for decrypting the complex genetic architecture of many diseases. Furthermore, GWA approaches have the potential to power a new generation of genetic tests, which one day may be used to estimate an individual's risk for a particular disease or to predict which chemotherapeutic agent or biological treatment will be most effective. As the costs decline and the analytical methods become more powerful, genetic testing may become a feasible option for patients seeking to understand the health risks conferred by the mutations residing in their DNA. Given their advancement to date, the current generation of neurosurgeons and neurologists can expect to use patient genetics as part of their clinical decision-making at the bedside.

\section{Disclosure}

The authors report no conflict of interest concerning the materials or methods used in this study or the findings specified in this paper.

\section{References}

1. Abecasis GR, Cherny SS, Cookson WO, Cardon LR: Merlinrapid analysis of dense genetic maps using sparse gene flow trees. Nat Genet 30:97-101, 2002

2. Abraham R, Moskvina V, Sims R, Hollingworth P, Morgan A, Georgieva L, et al: A genome-wide association study for lateonset Alzheimer's disease using DNA pooling. BMC Med Genomics 1:44, 2008

3. Abrahams BS, Geschwind DH: Advances in autism genetics: on the threshold of a new neurobiology. Nat Rev Genet 9:341-355, 2008

4. Altshuler D, Daly MJ, Lander ES: Genetic mapping in human disease. Science 322:881-888, 2008

5. Anney RJ, Lasky-Su J, O’Dúshláine C, Kenny E, Neale BM,
Mulligan A, et al: Conduct disorder and ADHD: evaluation of conduct problems as a categorical and quantitative trait in the international multicentre ADHD genetics study. Am J Med Genet B Neuropsychiatr Genet 147B:1369-1378, 2008

6. Aulchenko YS, Hoppenbrouwers IA, Ramagopalan SV, Broer L, Jafari N, Hillert J, et al: Genetic variation in the KIF1B locus influences susceptibility to multiple sclerosis. Nat Genet 40:1402-1403, 2008

7. Australia and New Zealand Multiple Sclerosis Genetics Consortium (ANZgene): Genome-wide association study identifies new multiple sclerosis susceptibility loci on chromosomes 12 and 20. Nat Genet 41:824-828, 2009

8. Autism Genome Project Consortium: Mapping autism risk loci using genetic linkage and chromosomal rearrangements. Nat Genet 39:319-328, 2007

9. Bae JS, Cheong HS, Kim JO, Lee SO, Kim EM, Lee HW, et al: Identification of SNP markers for common CNV regions and association analysis of risk of subarachnoid aneurysmal hemorrhage in Japanese population. Biochem Biophys Res Commun 373:593-596, 2008

10. de Bakker PI, Yelensky R, Pe'er I, Gabriel SB, Daly MJ, Altshuler D: Efficiency and power in genetic association studies. Nat Genet 37:1217-1223, 2005

11. Balding DJ: A tutorial on statistical methods for population association studies. Nat Rev Genet 7:781-791, 2006

12. Baranzini SE, Wang J, Gibson RA, Galwey N, Naegelin Y, Barkhof F, et al: Genome-wide association analysis of susceptibility and clinical phenotype in multiple sclerosis. Hum Mol Genet 18:767-778, 2009

13. Baum AE, Akula N, Cabanero M, Cardona I, Corona W, Klemens B, et al: A genome-wide association study implicates diacylglycerol kinase eta (DGKH) and several other genes in the etiology of bipolar disorder. Mol Psychiatry 13:197-207, 2008

14. Beckmann JS, Estivill X, Antonarakis SE: Copy number variants and genetic traits: closer to the resolution of phenotypic to genotypic variability. Nat Rev Genet 8:639-646, 2007

15. Beecham GW, Martin ER, Li YJ, Slifer MA, Gilbert JR, Haines JL, et al: Genome-wide association study implicates a chromosome 12 risk locus for late-onset Alzheimer disease. Am J Hum Genet 84:35-43, 2009

16. Benjamini Y, Hochberg Y: Controlling the false discovery rate: a practical and powerful approach to multiple testing. J Roy Stat Soc 57:289-300, 1995

17. Berrettini W, Yuan X, Tozzi F, Song K, Francks C, Chilcoat $\mathrm{H}$, et al: Alpha-5/alpha-3 nicotinic receptor subunit alleles increase risk for heavy smoking. Mol Psychiatry 13:368-373, 2008

18. Bertram L, Lange C, Mullin K, Parkinson M, Hsiao M, Hogan MF, et al: Genome-wide association analysis reveals putative Alzheimer's disease susceptibility loci in addition to APOE. Am J Hum Genet 83:623-632, 2008

19. Bierut LJ, Madden PA, Breslau N, Johnson EO, Hatsukami D, Pomerleau OF, et al: Novel genes identified in a high-density genome wide association study for nicotine dependence. Hum Mol Genet 16:24-35, 2007

20. Bilguvar K, Yasuno K, Niemelä M, Ruigrok YM, von Und Zu Fraunberg M, van Duijn CM, et al: Susceptibility loci for intracranial aneurysm in European and Japanese populations. Nat Genet 40:1472-1477, 2008

21. Blauw HM, Veldink JH, van Es MA, van Vught PW, Saris CG, van der Zwaag B, et al: Copy-number variation in sporadic amyotrophic lateral sclerosis: a genome-wide screen. Lancet Neurol 7:319-326, 2008

22. Bucan M, Abrahams BS, Wang K, Glessner JT, Herman EI, Sonnenblick LI, et al: Genome-wide analyses of exonic copy number variants in a family-based study point to novel autism susceptibility genes. PLoS Genet 5:e1000536, 2009

23. Cancer Genome Atlas Research Network: Comprehensive ge- 
nomic characterization defines human glioblastoma genes and core pathways. Nature 455:1061-1068, 2008

24. Capasso M, Devoto M, Hou C, Asgharzadeh S, Glessner JT, Attiyeh EF, et al: Common variations in BARD1 influence susceptibility to high-risk neuroblastoma. Nat Genet 41:718723,2009

25. Cardno AG, Holmans PA, Rees MI, Jones LA, McCarthy GM, Hamshere ML, et al: A genomewide linkage study of age at onset in schizophrenia. Am J Med Genet 105:439-445, 2001

26. Carrasquillo MM, Zou F, Pankratz VS, Wilcox SL, Ma L, Walker LP, et al: Genetic variation in PCDH11X is associated with susceptibility to late-onset Alzheimer's disease. Nat Genet 41:192-198, 2009

27. Chiò A, Schymick JC, Restagno G, Scholz SW, Lombardo F, Lai SL, et al: A two-stage genome-wide association study of sporadic amyotrophic lateral sclerosis. Hum Mol Genet 18:1524-1532, 2009

28. Comabella M, Craig DW, Camiña-Tato M, Morcillo C, Lopez C, Navarro A, et al : Identification of a novel risk locus for multiple sclerosis at $13 \mathrm{q} 31.3$ by a pooled genome-wide scan of 500,000 single nucleotide polymorphisms. PLoS One 3:e3490, 2008

29. Comabella M, Craig DW, Morcillo-Suárez C, Río J, Navarro A, Fernández M, et al: Genome-wide scan of 500,000 singlenucleotide polymorphisms among responders and nonresponders to interferon beta therapy in multiple sclerosis. Arch Neurol 66:972-978, 2009

30. Cordell HJ: Epistasis: what it means, what it doesn't mean, and statistical methods to detect it in humans. Hum Mol Genet 11:2463-2468, 2002

31. Cordell HJ: Estimation and testing of gene-environment interactions in family-based association studies. Genomics 93:5-9, 2009

32. Cordell HJ: Genome-wide association studies: detecting genegene interactions that underlie human diseases. Nat Rev Genet 10:392-404, 2009

33. Cordell HJ, Barratt BJ, Clayton DG: Case/pseudocontrol analysis in genetic association studies: a unified framework for detection of genotype and haplotype associations, gene-gene and gene-environment interactions, and parent-of-origin effects. Genet Epidemiol 26:167-185, 2004

34. Cronin S, Berger S, Ding J, Schymick JC, Washecka N, Hernandez DG, et al: A genome-wide association study of sporadic ALS in a homogenous Irish population. Hum Mol Genet 17:768-774, 2008

35. Cronin S, Tomik B, Bradley DG, Slowik A, Hardiman O: Screening for replication of genome-wide SNP associations in sporadic ALS. Eur J Hum Genet 17:213-218, 2009

36. Desautels A, Turecki G, Montplaisir J, Sequeira A, Verner A, Rouleau GA: Identification of a major susceptibility locus for restless legs syndrome on chromosome 12q. Am J Hum Genet 69:1266-1270, 2001

37. Drgon T, Montoya I, Johnson C, Liu QR, Walther D, Hamer D, et al: Genome-wide association for nicotine dependence and smoking cessation success in NIH research volunteers. Mol Med 15:21-27, 2009

38. Dunckley T, Huentelman MJ, Craig DW, Pearson JV, Szelinger S, Joshipura K, et al: Whole-genome analysis of sporadic amyotrophic lateral sclerosis. N Engl J Med 357:775-788, 2007

39. Farrer MJ, Haugarvoll K, Ross OA, Stone JT, Milkovic NM, Cobb SA, et al: Genomewide association, Parkinson disease, and PARK10. Am J Hum Genet 78:1084-1088, author reply 1092-1094, 2006

40. Ferreira MA, O’Donovan MC, Meng YA, Jones IR, Ruderfer $\mathrm{DM}$, Jones L, et al : Collaborative genome-wide association analysis supports a role for ANK3 and CACNA1C in bipolar disorder. Nat Genet 40:1056-1058, 2008

41. Feulner TM, Laws SM, Friedrich P, Wagenpfeil S, Wurst SH,
Riehle C, et al: Examination of the current top candidate genes for AD in a genome-wide association study. Mol Psychiatry [epub ahead of print], 2009

42. Fung HC, Scholz S, Matarin M, Simón-Sánchez J, Hernandez $\mathrm{D}$, Britton A, et al: Genome-wide genotyping in Parkinson's disease and neurologically normal controls: first stage analysis and public release of data. Lancet Neurol 5:911-916, 2006

43. Furnari FB, Fenton T, Bachoo RM, Mukasa A, Stommel JM, Stegh A, et al: Malignant astrocytic glioma: genetics, biology, and paths to treatment. Genes Dev 21:2683-2710, 2007

44. Gao X, Gordon D, Zhang D, Browne R, Helms C, Gillum J, et al: CHD7 gene polymorphisms are associated with susceptibility to idiopathic scoliosis. Am J Hum Genet 80:957-965, 2007

45. Glessner JT, Wang K, Cai G, Korvatska O, Kim CE, Wood $\mathrm{S}$, et al: Autism genome-wide copy number variation reveals ubiquitin and neuronal genes. Nature 459:569-573, 2009

46. Gottlieb DJ, O'Connor GT, Wilk JB: Genome-wide association of sleep and circadian phenotypes. BMC Med Genet 8 (1 Suppl):S9, 2007

47. Gretarsdottir S, Thorleifsson G, Manolescu A, Styrkarsdottir U, Helgadottir A, Gschwendtner A, et al: Risk variants for atrial fibrillation on chromosome $4 \mathrm{q} 25$ associate with ischemic stroke. Ann Neurol 64:402-409, 2008

48. Grosse SD, Khoury MJ: What is the clinical utility of genetic testing? Genet Med 8:448-450, 2006

49. Grosse SD, Rogowski WH, Ross LF, Cornel MC, Dondorp WJ, Khoury MJ: Population screening for genetic disorders in the 21st century: evidence, economics, and ethics. Public Health Genomics [epub ahead of print], 2009

50. Hartl DL, Clark AG: Principles of Population Genetics. Sunderland, MA: Sinauer, 2007

51. Hattori E, Toyota T, Ishitsuka Y, Iwayama Y, Yamada K, Ujike $\mathrm{H}$, et al. Preliminary genome-wide association study of bipolar disorder in the Japanese population. Am J Med Genet B Neuropsychiatr Genet [epub ahead of print], 2009

52. Hindorff LA, Junkins HA, Mehta JP, Manolio TA: A catalog of published genome-wide association studies. www.genome. gov/gwastudies [Accessed October 27, 2009]

53. Hindorff LA, Sethupathy P, Junkins HA, Ramos EM, Mehta JP, Collins FS, et al: Potential etiologic and functional implications of genome-wide association loci for human diseases and traits. Proc Natl Acad Sci U S A 106:9362-9367, 2009

54. Hirschhorn JN, Daly MJ: Genome-wide association studies for common diseases and complex traits. Nat Rev Genet 6:95-108, 2005

55. Hoggart CJ, Whittaker JC, De Iorio M, Balding DJ: Simultaneous analysis of all SNPs in genome-wide and re-sequencing association studies. PLoS Genet 4:e1000130, 2008

56. International HapMap Consortium: A second generation human haplotype map of over 3.1 million SNPs. Nature 449: 851-861, 2007

57. International Multiple Sclerosis Genetics Consortium: Risk alleles for multiple sclerosis identified by a genomewide study. N Engl J Med 357:851-862, 2007

58. International Schizophrenia Consortium: Common polygenic variation contributes to risk of schizophrenia and bipolar disorder. Nature 460:748-752, 2009

59. De Jager PL, Jia X, Wang J, de Bakker PI, Ottoboni L, Aggarwal NT, et al: Meta-analysis of genome scans and replication identify CD6, IRF8 and TNFRSF1A as new multiple sclerosis susceptibility loci. Nat Genet 41:776-782, 2009

60. Kim H, Ramsay E, Lee H, Wahl S, Dionne RA: Genomewide association study of acute post-surgical pain in humans. Pharmacogenomics 10:171-179, 2009

61. Kirov G, Zaharieva I, Georgieva L, Moskvina V, Nikolov I, Cichon S, et al: A genome-wide association study in 574 schizophrenia trios using DNA pooling. Mol Psychiatry 14:796-803, 2009 
62. Klein RJ, Zeiss C, Chew EY, Tsai JY, Sackler RS, Haynes $\mathrm{C}$, et al: Complement factor $\mathrm{H}$ polymorphism in age-related macular degeneration. Science 308:385-389, 2005

63. Landers JE, Melki J, Meininger V, Glass JD, van den Berg LH, van Es MA, et al: Reduced expression of the kinesin-associated protein 3 (KIFAP3) gene increases survival in sporadic amyotrophic lateral sclerosis. Proc Natl Acad Sci U S A 106:9004-9009, 2009

64. Lasky-Su J, Anney RJ, Neale BM, Franke B, Zhou K, Maller $\mathrm{JB}$, et al: Genome-wide association scan of the time to onset of attention deficit hyperactivity disorder. Am J Med Genet B Neuropsychiatr Genet 147B:1355-1358, 2008

65. Lasky-Su J, Neale BM, Franke B, Anney RJ, Zhou K, Maller $\mathrm{JB}$, et al: Genome-wide association scan of quantitative traits for attention deficit hyperactivity disorder identifies novel associations and confirms candidate gene associations. Am J Med Genet B Neuropsychiatr Genet 147B:1345-1354, 2008

66. Lencz T, Morgan TV, Athanasiou M, Dain B, Reed CR, Kane JM, et al: Converging evidence for a pseudoautosomal cytokine receptor gene locus in schizophrenia. Mol Psychiatry 12:572-580, 2007

67. Lesage S, Brice A: Parkinson's disease: from monogenic forms to genetic susceptibility factors. Hum Mol Genet 18 (R1):R48-R59, 2009

68. Lesch KP, Timmesfeld N, Renner TJ, Halperin R, Röser C, Nguyen TT, et al: Molecular genetics of adult ADHD: converging evidence from genome-wide association and extended pedigree linkage studies. J Neural Transm 115:1573-1585, 2008

69. Li M, Boehnke M, Abecasis GR: Efficient study designs for test of genetic association using sibship data and unrelated cases and controls. Am J Hum Genet 78:778-792, 2006

70. Li M, Boehnke M, Abecasis GR: Joint modeling of linkage and association: identifying SNPs responsible for a linkage signal. Am J Hum Genet 76:934-949, 2005

71. Li A, Walling J, Ahn S, Kotliarov Y, Su Q, Quezado M, et al: Unsupervised analysis of transcriptomic profiles reveals six glioma subtypes. Cancer Res 69:2091-2099, 2009

72. Li H, Wetten S, Li L, St Jean PL, Upmanyu R, Surh L, et al: Candidate single-nucleotide polymorphisms from a genomewide association study of Alzheimer disease. Arch Neurol 65:45-53, 2008

73. Liu F, Arias-Vásquez A, Sleegers K, Aulchenko YS, Kayser M, Sanchez-Juan P, et al: A genomewide screen for late-onset Alzheimer disease in a genetically isolated Dutch population. Am J Hum Genet 81:17-31, 2007

74. Louis DN: Molecular pathology of malignant gliomas. Annu Rev Pathol 1:97-117, 2006

75. Ma D, Salyakina D, Jaworski JM, Konidari I, Whitehead PL, Andersen AN, et al: A genome-wide association study of autism reveals a common novel risk locus at 5p14.1. Ann Hum Genet 73:263-273, 2009

76. Maraganore DM, de Andrade M, Lesnick TG, Strain KJ, Farrer MJ, Rocca WA, et al: High-resolution whole-genome association study of Parkinson disease. Am J Hum Genet 77:685-693, 2005

77. Maris JM, Mosse YP, Bradfield JP, Hou C, Monni S, Scott RH, et al: Chromosome 6p22 locus associated with clinically aggressive neuroblastoma. N Engl J Med 358:2585-2593, 2008

78. Marko NF, Toms SA, Barnett GH, Weil R: Genomic expression patterns distinguish long-term from short-term glioblastoma survivors: a preliminary feasibility study. Genomics 91:395-406, 2008

79. Matarín M, Brown WM, Scholz S, Simón-Sánchez J, Fung $\mathrm{HC}$, Hernandez D, et al: A genome-wide genotyping study in patients with ischaemic stroke: initial analysis and data release. Lancet Neurol 6:414-420, 2007
80. McCarthy MI, Abecasis GR, Cardon LR, Goldstein DB, Little J, Ioannidis JP, et al: Genome-wide association studies for complex traits: consensus, uncertainty and challenges. Nat Rev Genet 9:356-369, 2008

81. Mead S, Poulter M, Uphill J, Beck J, Whitfield J, Webb TE, et al: Genetic risk factors for variant Creutzfeldt-Jakob disease: a genome-wide association study. Lancet Neurol 8:57-66, 2009

82. Melquist S, Craig DW, Huentelman MJ, Crook R, Pearson JV, Baker M, et al: Identification of a novel risk locus for progressive supranuclear palsy by a pooled genomewide scan of 500,288 single-nucleotide polymorphisms. Am J Hum Genet 80:769-778, 2007

83. Mick E, Neale B, Middleton FA, McGough JJ, Faraone SV: Genome-wide association study of response to methylphenidate in 187 children with attention-deficit/hyperactivity disorder. Am J Med Genet B Neuropsychiatr Genet 147B:14121418,2008

84. Mladkova N, Chakravarti A: Molecular profiling in glioblastoma: prelude to personalized treatment. Curr Oncol Rep 11:53-61, 2009

85. Muglia P, Tozzi F, Galwey NW, Francks C, Upmanyu R, Kong $\mathrm{XQ}$, et al: Genome-wide association study of recurrent major depressive disorder in two European case-control cohorts. Mol Psychiatry [epub ahead of print], 2008

86. Nakamura M, Shimada K, Ishida E, Nakase H, Konishi N: Genetic analysis to complement histopathological diagnosis of brain tumors. Histol Histopathol 22:327-335, 2007

87. Neale BM, Lasky-Su J, Anney R, Franke B, Zhou K, Maller $\mathrm{JB}$, et al: Genome-wide association scan of attention deficit hyperactivity disorder. Am J Med Genet B Neuropsychiatr Genet 147B:1337-1344, 2008

88. Need AC, Ge D, Weale ME, Maia J, Feng S, Heinzen EL, et al: A genome-wide investigation of SNPs and CNVs in schizophrenia. PLoS Genet 5:e1000373, 2009

89. O'Donovan MC, Craddock N, Norton N, Williams H, Peirce $\mathrm{T}$, Moskvina V, et al : Identification of loci associated with schizophrenia by genome-wide association and follow-up. Nat Genet 40:1053-1055, 2008

90. Oksenberg JR, Baranzini SE, Sawcer S, Hauser SL: The genetics of multiple sclerosis: SNPs to pathways to pathogenesis. Nat Rev Genet 9:516-526, 2008

91. Otowa T, Yoshida E, Sugaya N, Yasuda S, Nishimura Y, Inoue $\mathrm{K}$, et al: Genome-wide association study of panic disorder in the Japanese population. J Hum Genet 54:122-126, 2009

92. Paassilta P, Lohiniva J, Göring HH, Perälä M, Räinä SS, Karppinen $\mathrm{J}$, et al: Identification of a novel common genetic risk factor for lumbar disk disease. JAMA 285:1843-1849, 2001

93. Pankratz N, Wilk JB, Latourelle JC, DeStefano AL, Halter C, Pugh EW, et al: Genomewide association study for susceptibility genes contributing to familial Parkinson disease. Hum Genet 124:593-605, 2009

94. Papassotiropoulos A, Stephan DA, Huentelman MJ, Hoerndli FJ, Craig DW, Pearson JV, et al: Common Kibra alleles are associated with human memory performance. Science 314:475-478, 2006

95. Parsons DW, Jones S, Zhang X, Lin JC-H, Leary RJ, Angenendt $\mathrm{P}$, et al: An integrated genomic analysis of human glioblastoma multiforme. Science 321:1807-1812, 2008

96. Poduslo SE, Huang R, Huang J, Smith S: Genome screen of late-onset Alzheimer's extended pedigrees identifies TRPC4AP by haplotype analysis. Am J Med Genet B Neuropsychiatr Genet 150B:50-55, 2009

97. Poduslo SE, Huang R, Spiro A. A genome screen of successful aging without cognitive decline identifies LRP1B by haplotype analysis. Am J Med Genet B Neuropsychiatr Genet [epub ahead of print], 2009

98. Pritchard JK: Are rare variants responsible for susceptibility to complex diseases? Am J Hum Genet 69:124-137, 2001 
99. Purcell S, Neale B, Todd-Brown K, Thomas L, Ferreira MA, Bender D, et al: PLINK: a tool set for whole-genome association and population-based linkage analyses. Am J Hum Genet 81:559-575, 2007

100. Reich DE, Lander ES: On the allelic spectrum of human disease. Trends Genet 17:502-510, 2001

101. Rogowski W: Current impact of gene technology on healthcare. A map of economic assessments. Health Policy 80:340-357, 2007

102. Rogowski W: Genetic screening by DNA technology: a systematic review of health economic evidence. Int J Technol Assess Health Care 22:327-337, 2006

103. Schjeide BM, Hooli B, Parkinson M, Hogan MF, DiVito J, Mullin K, et al: GAB2 as an Alzheimer disease susceptibility gene: follow-up of genomewide association results. Arch Neurol 66:250-254, 2009

104. Schormair B, Kemlink D, Roeske D, Eckstein G, Xiong L, Lichtner P, et al: PTPRD (protein tyrosine phosphatase receptor type delta) is associated with restless legs syndrome. Nat Genet 40:946-948, 2008

105. Schymick JC, Scholz SW, Fung HC, Britton A, Arepalli S, Gibbs JR, et al: Genome-wide genotyping in amyotrophic lateral sclerosis and neurologically normal controls: first stage analysis and public release of data. Lancet Neurol 6:322-328, 2007

106. Scott LJ, Muglia P, Kong XQ, Guan W, Flickinger M, Upmanyu $\mathrm{R}$, et al: Genome-wide association and meta-analysis of bipolar disorder in individuals of European ancestry. Proc Natl Acad Sci U S A 106:7501-7506, 2009

107. Sebat J, Lakshmi B, Malhotra D, Troge J, Lese-Martin C, Walsh $\mathrm{T}$, et al: Strong association of de novo copy number mutations with autism. Science 316:445-449, 2007

108. Seshadri S, DeStefano AL, Au R, Massaro JM, Beiser AS, Kelly-Hayes M, et al: Genetic correlates of brain aging on MRI and cognitive test measures: a genome-wide association and linkage analysis in the Framingham Study. BMC Med Genet 8 (1 Suppl):S15, 2007

109. Shete S, Hosking FJ, Robertson LB, Dobbins SE, Sanson M, Malmer B, et al: Genome-wide association study identifies five susceptibility loci for glioma. Nat Genet 41:899-904, 2009

110. Shi J, Levinson DF, Duan J, Sanders AR, Zheng Y, Pe'er I, et al: Common variants on chromosome 6 p22.1 are associated with schizophrenia. Nature 460:753-757, 2009

111. Shifman S, Bhomra A, Smiley S, Wray NR, James MR, Martin NG, et al: A whole genome association study of neuroticism using DNA pooling. Mol Psychiatry 13:302-312, 2008

112. Shifman S, Johannesson M, Bronstein M, Chen SX, Collier DA, Craddock NJ, et al: Genome-wide association identifies a common variant in the reelin gene that increases the risk of schizophrenia only in women. PLoS Genet 4:e28, 2008

113. Simón-Sánchez J, Scholz S, Matarin Mdel M, Fung HC, Hernandez D, Gibbs JR, et al: Genomewide SNP assay reveals mutations underlying Parkinson disease. Hum Mutat 29:315322, 2008

114. Simón-Sánchez J, Singleton A: Genome-wide association studies in neurological disorders. Lancet Neurol 7:1067-1072, 2008

115. Sklar P, Smoller JW, Fan J, Ferreira MA, Perlis RH, Chambert $\mathrm{K}$, et al: Whole-genome association study of bipolar disorder. Mol Psychiatry 13:558-569, 2008

116. Smith EN, Bloss CS, Badner JA, Barrett T, Belmonte PL, Berrettini $\mathrm{W}$, et al: Genome-wide association study of bipolar disorder in European American and African American individuals. Mol Psychiatry 14:755-763, 2009

117. Sonuga-Barke EJ, Lasky-Su J, Neale BM, Oades R, Chen W, Franke B, et al: Does parental expressed emotion moderate genetic effects in ADHD? An exploration using a genome wide association scan. Am J Med Genet B Neuropsychiatr Genet 147B:1359-1368, 2008

118. Stefansson H, Ophoff RA, Steinberg S, Andreassen OA, Cichon
S, Rujescu D, et al: Common variants conferring risk of schizophrenia. Nature 460:744-747, 2009

119. Stefansson H, Rujescu D, Cichon S, Pietiläinen OPH, Ingason A, Steinberg S, et al: Large recurrent microdeletions associated with schizophrenia. Nature 455:232-236, 2008

120. Sullivan PF, de Geus EJ, Willemsen G, James MR, Smit JH, Zandbelt T, et al: Genome-wide association for major depressive disorder: a possible role for the presynaptic protein piccolo. Mol Psychiatry 14:359-375, 2009

121. Sullivan PF, Lin D, Tzeng JY, van den Oord E, Perkins D, Stroup TS, et al: Genomewide association for schizophrenia in the CATIE study: results of stage 1. Mol Psychiatry 13:570-584, 2008

122. Sulman EP, Guerrero M, Aldape K: Beyond grade: molecular pathology of malignant gliomas. Semin Radiat Oncol 19:142149,2009

123. Terracciano A, Sanna S, Uda M, Deiana B, Usala G, Busonero F, et al: Genome-wide association scan for five major dimensions of personality. Mol Psychiatry [epub ahead of print], 2008

124. Thorgeirsson TE, Geller F, Sulem P, Rafnar T, Wiste A, Magnusson KP, et al: A variant associated with nicotine dependence, lung cancer and peripheral arterial disease. Nature 452: 638-642, 2008

125. Treutlein J, Cichon S, Ridinger M, Wodarz N, Soyka M, Zill P, et al: Genome-wide association study of alcohol dependence. Arch Gen Psychiatry 66:773-784, 2009

126. Uhl GR, Drgon T, Liu QR, Johnson C, Walther D, Komiyama $\mathrm{T}$, et al: Genome-wide association for methamphetamine dependence: convergent results from 2 samples. Arch Gen Psychiatry 65:345-355, 2008

127. Uhl GR, Liu QR, Drgon T, Johnson C, Walther D, Rose JE: Molecular genetics of nicotine dependence and abstinence: whole genome association using 520,000 SNPs. BMC Genet 8:10, 2007

128. van den Oord EJ, Kuo PH, Hartmann AM, Webb BT, Möller HJ, Hettema JM, et al: Genomewide association analysis followed by a replication study implicates a novel candidate gene for neuroticism. Arch Gen Psychiatry 65:1062-1071, 2008

129. van Es MA, Van Vught PW, Blauw HM, Franke L, Saris CG, Andersen PM, et al: ITPR2 as a susceptibility gene in sporadic amyotrophic lateral sclerosis: a genome-wide association study. Lancet Neurol 6:869-877, 2007

130. van Es MA, van Vught PW, Blauw HM, Franke L, Saris CG, Van den Bosch L, et al: Genetic variation in DPP6 is associated with susceptibility to amyotrophic lateral sclerosis. Nat Genet 40:29-31, 2008

131. Virtanen IM, Noponen N, Barral S, Karppinen J, Li H, Vuoristo $\mathrm{M}$, et al: Putative susceptibility locus on chromosome 21q for lumbar disc disease (LDD) in the Finnish population. J Bone Miner Res 22:701-707, 2007

132. Walsh T, McClellan JM, McCarthy SE, Addington AM, Pierce SB, Cooper GM, et al: Rare structural variants disrupt multiple genes in neurodevelopmental pathways in schizophrenia. Science 320:539-543, 2008

133. Wang K, Zhang H, Ma D, Bucan M, Glessner JT, Abrahams BS, et al: Common genetic variants on 5 p14.1 associate with autism spectrum disorders. Nature 459:528-533, 2009

134. Wang WY, Barratt BJ, Clayton DG, Todd JA: Genome-wide association studies: theoretical and practical concerns. Nat Rev Genet 6:109-118, 2005

135. Waring SC, Rosenberg RN: Genome-wide association studies in Alzheimer disease. Arch Neurol 65:329-334, 2008

136. Webster JA, Myers AJ, Pearson JV, Craig DW, Hu-Lince D, Coon KD, et al: Sorl1 as an Alzheimer's disease predisposition gene? Neurodegener Dis 5:60-64, 2008

137. Wellcome Trust Case Control Consortium: Genome-wide association study of 14,000 cases of seven common diseases and 3,000 shared controls. Nature 447:661-678, 2007

138. Williams NM, Norton N, Williams H, Ekholm B, Hamshere 
ML, Lindblom Y, et al: A systematic genomewide linkage study in 353 sib pairs with schizophrenia. Am J Hum Genet 73:1355-1367, 2003

139. Winkelmann J, Schormair B, Lichtner P, Ripke S, Xiong L, Jalilzadeh $\mathrm{S}$, et al: Genome-wide association study of restless legs syndrome identifies common variants in three genomic regions. Nat Genet 39:1000-1006, 2007

140. Wise CA, Barnes R, Gillum J, Herring JA, Bowcock AM, Lovett M: Localization of susceptibility to familial idiopathic scoliosis. Spine (Phila Pa 1976) 25:2372-2380, 2000

141. Wise CA, Gao X, Shoemaker S, Gordon D, Herring JA: Understanding genetic factors in idiopathic scoliosis, a complex disease of childhood. Curr Genomics 9:51-59, 2008

142. Wittke-Thompson JK, Pluzhnikov A, Cox NJ: Rational inferences about departures from Hardy-Weinberg equilibrium. Am J Hum Genet 76:967-986, 2005

143. Wrensch M, Jenkins RB, Chang JS, Yeh RF, Xiao Y, Decker $\mathrm{PA}$, et al: Variants in the CDKN2B and RTEL1 regions are associated with high-grade glioma susceptibility. Nat Genet 41:905-908, 2009

144. Yamada Y, Fuku N, Tanaka M, Aoyagi Y, Sawabe M, Metoki $\mathrm{N}$, et al: Identification of CELSR1 as a susceptibility gene for ischemic stroke in Japanese individuals by a genome-wide association study. J Atherosclerosis [epub ahead of print], 2009

145. Zhang D, Cheng L, Qian Y, Alliey-Rodriguez N, Kelsoe JR, Greenwood T, et al: Singleton deletions throughout the genome increase risk of bipolar disorder. Mol Psychiatry 14:376-380, 2009

Manuscript submitted August 12, 2009

Accepted October 5, 2009.

Address correspondence to: Matthew C. Cowperthwaite, Ph.D., NeuroTexas Institute, 1015 East 32nd Street, Suite 404, Austin, Texas 78705. email: matthew.cowperthwaite@stdavids.com. 